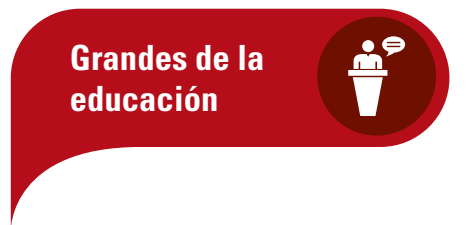

\title{
Mohandas Karamchand Gandhi (1869-1948)
}
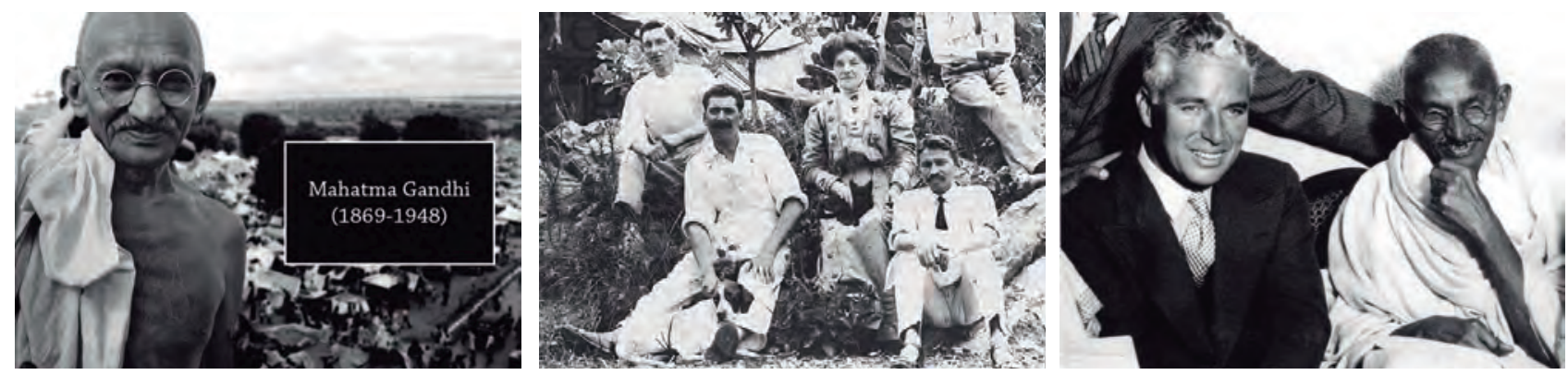

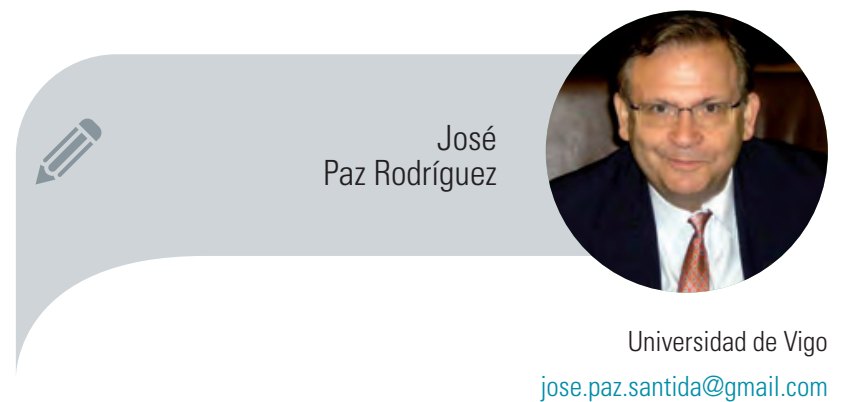

El 2 de octubre de 1869 nace en Porbandar, ciudad hoy del estado indio de Gujarat, Mohandas Karamchand Gandhi, al que en 1915 Robindronath Tagore le da el apelativo de "Mahatma", palabra sánscrita que significa "Alma Grande", por el que es conocido en el mundo. Y que Albert Einstein consideraba como "el hombre más grande de nuestro siglo".

Existen muchas e interesantes biografías de Gandhi, publicadas en castellano, que pueden ser leídas para profundizar en su vida, en su formación, en su origen, en sus lecturas, en la creación de sus 4 instituciones educativas y en la lucha pacífica que llevó a cabo con sus seguidores para al final lograr en 1947 la independencia de su país.

Conviene recordar sin embargo que Gandhi visitó la escuela nueva Santiniketon de Tagore por tres veces, en los años 1915, 1934 y 1940. Estas visitas fueron muy importantes, especialmente la primera, para cambiar por su influencia algunas normas educativas de la "Morada de la Paz" tagoreana.

El 20 de enero de 1948, en Nueva Delhi, Gandhi sufre un atentado con bomba. Y el 30 del mismo mes, poco después de la cinco de la tarde, muere asesinado cuando se disponía a orar, por los tiros del revólver del fanático hindú Nathuram Godse, miembro de un grupo fundamentalista que lo apoyaba y que, por des- gracia, todavía persiste en el país. El lugar de Delhi donde fue asesinado es hoy un museo al aire libre, recordando el triste hecho, que es muy visitado por los indios y los extranjeros amantes del legado de paz y no violencia que nos dejó el "Mahatma" Gandhi.

\section{Instituciones educativas creadas por Gandhi}

1. Granja escolar Phoenix: Sudáfrica (1904). Para demostrar las posibilidades de vida en una comuna rural. Ruskin con su obra Unto this Last, leída por Gandhi, fue la inspiración para crear esta institución educativa. En esta institución puso en práctica por primera vez la clase de vida que su propuesta de educación básica consideraba más beneficiosa.

2. Granja escolar Tolstoy: Sudáfrica (1910). Mejora de los métodos utilizados en la Phoenix. Gandhi admiraba al pedagogo y escritor ruso, del que había leído bastantes obras y llegó a ponerse en contacto con él a través de una interesante correspondencia. Tolstoy inspiró a Gandhi en una amplia variedad de intereses y preocupaciones como, por ejemplo, la lucha contra las fuentes de la violencia en la sociedad humana.

3. Sabarmati-Ashram: Kocharab Bungalow de Jivanlal Desai (1915), transferido el 17 de junio de 1917 a un lugar al lado del río Sabarmati, para poder realizar actividades agrícolas y ganaderas. Cerca de Ahmedabad (India), creado tres meses después de llegar a su país y que hoy es un monumento nacional indio en recuerdo de la lucha por la independencia. En esta institución continúa con sus métodos de autosuficiencia y vida cooperativa y en paz.

4. Sevagram-Ashram: Segaon (Maharashtra), a 8 kilómetros de Wardha (1936). Gandhi decide residir aquí los últimos años de su vida, de 1936 a 

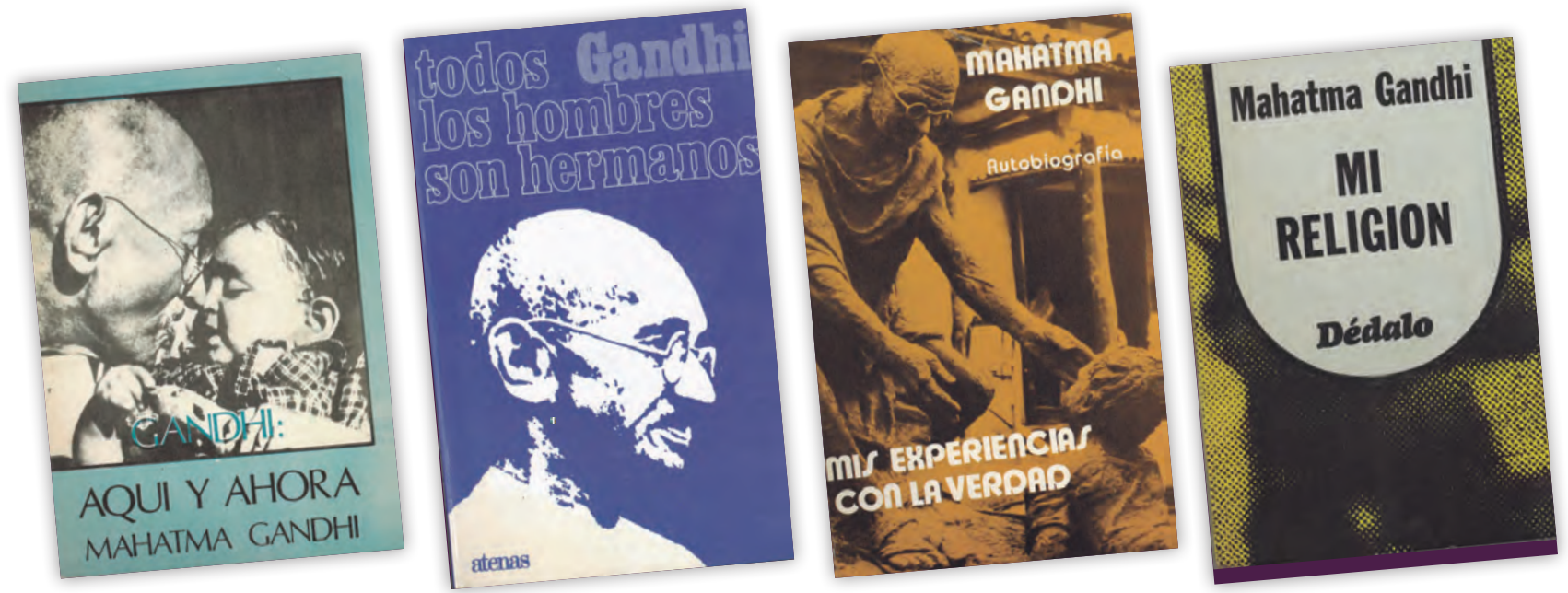

1948. Alrededor del "ashram-escuela" se reunían los discípulos y seguidores de Gandhi (su "gurú"). Los moradores tenían que hacer varios votos, comprometiéndose a ser siempre no violentos en pensamientos, palabras o hechos, a ser veraces aun a costa de sus vidas, a controlar su paladar consumiendo preferentemente no más de cinco artículos alimenticios al día, y a no comer jamás después de la puesta del sol.

\section{Aspectos educativos básicos de la pedagogía de Gandhi}

1. Modelo de maestro-educador: este texto gandhiano publicado dentro de su autobiografía resume magníficamente lo que pensaba sobre cómo debía ser el maestro o educador:

"Es imposible que un instructor, a kilómetros de distancia, influencie por su modo de vida el espíritu de los alumnos. Para mí, sería inútil enseñar a los niños a decir la verdad si yo fuese un mentiroso. Un maestro cobarde jamás conseguirá hacer valientes a sus discípulos, y un desconocedor del autocontrol no pasará para sus alumnos el valor de la autodisciplina. Vi, por tanto, que precisaría ser un eterno objeto-lección para niños y niñas que vivían conmigo. De esta forma ellos se volvían mis profesores/maestros, y así aprendí que tengo que ser bueno y vivir con rectitud, si no por mí, por lo menos por ellos. Puedo decir que la disciplina y el autocontrol, cada vez mayores, que me impuso la granja-escuela 'Tolstoy' eran debidos principalmente a esos mis guardianes".

2. Modelo de Educación Básica ("Nai Talim" o nueva educación): los rasgos fundamentales del modelo de la nueva educación propuesto por Gandhi, que bautizó con la denominación de "Nai Talim", son los siguientes:

7 La educación debe plantearse no solo la creación de un orden social justo, democrático y pacífico basado en sanciones no violentas, sino también indicar clara y precisamente los métodos para alcanzar este objetivo. Por lo que debe iniciarse desde la más tierna infancia y durar toda la vida.

$\boldsymbol{7}$ La escuela debe ayudar al desarrollo de la personalidad total del estudiante, sacando a la superficie sus talentos y relacionándolos armoniosamente entre sí. La educación del espíritu y del intelecto deben concurrir con la de toda aptitud física, llevando a un sistema creativo centrado en la vida, porque la vida y el trabajo deben ir juntos.

入 Las artesanías que producen artículos bellos y útiles ocupan el centro del proceso educativo para los alumnos y alumnas del sistema educativo. La finalidad de este sistema no es nunca la simple producción de artículos. El trabajo productivo es únicamente un medio para un fin, que es la completa educación del alumno.

$\boldsymbol{\lambda}$ La educación se obtiene de tres principales fuentes que relacionan el campo del saber con el ambiente natural, el ambiente social y los procesos del trabajo productivo. El alumno echa sus raíces en su propio suelo y desarrolla una visión cada vez más amplia de la vida, sus propósitos y sus deberes.

$\boldsymbol{7}$ El desarrollo del sentido de libertad, iniciativa y responsabilidad debe lograrse mediante la autonomía y la propia ayuda de los alumnos dentro de la comunidad escolar y esto supone naturalmente la abolición de los "exámenes de policía", eliminando la vigilancia de los docentes.

$\boldsymbol{7}$ La escuela debe estar estrechamente enlazada con la comunidad y viceversa.

$\boldsymbol{\eta}$ Los alumnos se convierten progresivamente en ciudadanos libres y cooperantes de una sociedad democrática, en la que no habrá altos ni bajos, ni distinciones de casta o clase, y en la 


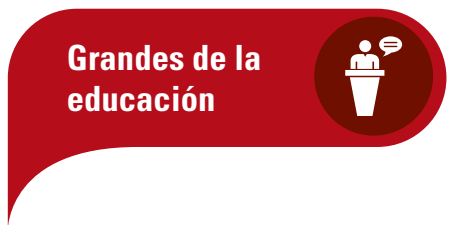

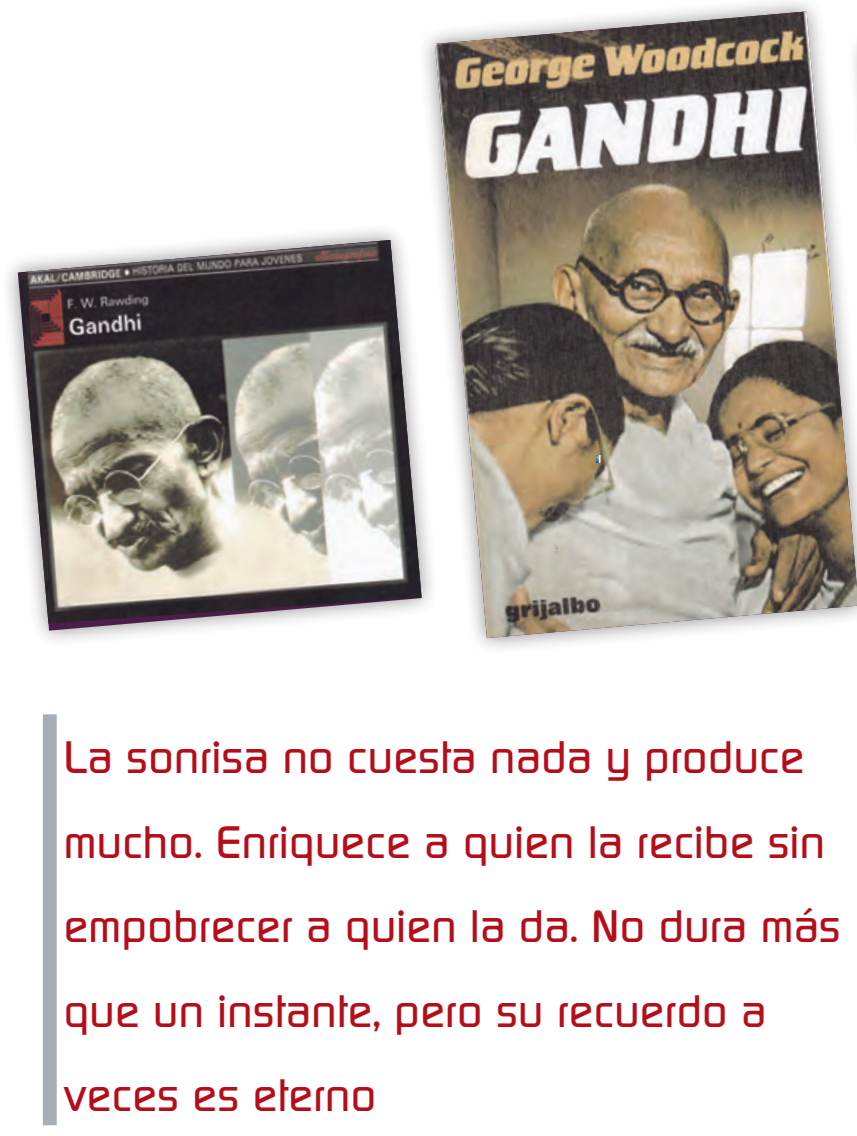

que se estará por la justicia y la paz. La escuela se convierte así en el punto de partida de una revolución no violenta en procura de un nuevo orden social.

入 La música debe tener su propio lugar en la rutina educativa. Los cantos llevan ritmo a las tareas y aligeran el esfuerzo de los que aprenden.

$\boldsymbol{\lambda}$ Los talleres escolares deben tener su debido valor, pues se bastan a sí mismos. El adiestramiento de la vista, el oído y la mano es absolutamente necesario y el trabajo manual debe ser obligatorio en todas las escuelas. El adiestramiento de la mano es realmente un adiestramiento del cerebro.

त Cuando una práctica en matemáticas, ciencias o geografía se repite todos los días durante años embota la mente y la hace caminar por surcos.

3. Enseñanza de la religión: la pedagogía de Gandhi -aun siendo él profundamente religioso, todos los días oraba y meditaba- era exclusivamente laica. En su plan de educación básica no se prevé la enseñanza de la religión. En junio de 1938 una delegación de educadores le preguntó sobre este asunto y él respondió: "Hemos dejado la enseñanza de la religión fuera del plan educativo 'Wardha' porque tememos que las religiones, tal como hoy
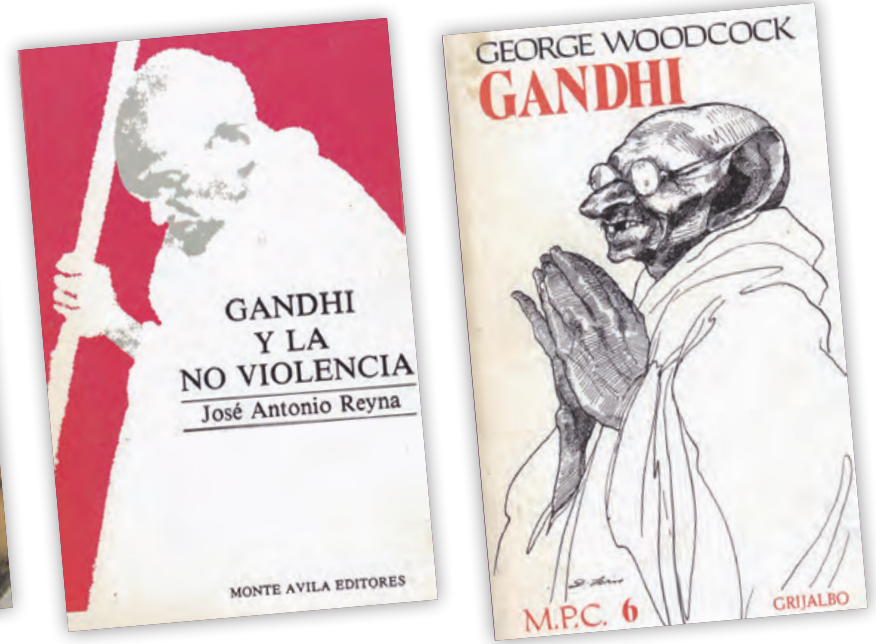

se enseñan y practican, nos llevan al conflicto más que a la unidad. Pero yo sostengo, por otra parte, que las verdades comunes a todas las religiones pueden y deben enseñarse a todos los niños. Estas verdades no pueden enseñarse con palabras o libros, ya que los niños solo podrán aprenderlas a través del ejemplo cotidiano del maestro. Solo si el maestro vive de acuerdo con los principios de la verdad y la justicia, podrán los niños aprender que la verdad y la justicia son la base de todas las religiones".

4. El currículo básico de sus instituciones educativas: esencialmente el currículo básico de las instituciones educativas gandhianas era el siguiente:

入 Conocimientos básicos de lectura, escritura y cálculo, para aplicar a la vida y el trabajo diario.

ᄁ Educación moral y ética, especialmente predicando con el ejemplo del educador.

त Autosuficiencia y vida cooperativa y en paz y armonía, desarrollando valores y actitudes positivas.

入 Desarrollo de la meditación personal.

$\boldsymbol{\eta}$ Trabajos manuales: industrias populares de tejido a mano y con la rueca, telares, carpintería, curtidos, alfarería, cestería, encuadernación, cerámica, herrería, etc. para lograr una artesanía productiva.

$\boldsymbol{7}$ Cuidado de animales y plantas: agricultura, cultivos, jardinería y ganadería.

- Educación para la paz y la no violencia, siguiendo el modelo gandhiano del "Satyagraha". Importancia de la conducta no violenta, tanto en pensamientos, como en palabras y hechos. Y del valor de la honestidad.

- Aprendizaje y uso de la lengua materna de los escolares, en lugar del inglés.

$\boldsymbol{\lambda}$ Ciencias aplicadas a los recursos naturales del entorno.

ᄁ Educación musical y estética. 


\section{Antología de textos pedagógicos de Gandhi}

Tomados de sus publicaciones periódicas de carácter semanal YI (Young India/Joven India) y H (Harijan), seleccionamos los siguientes textos pedagógicos gandhianos:

"No es deber del hombre desarrollar hasta la perfección todas sus facultades. Su deber consiste en perfeccionar al máximo sus facultades para con Dios y suprimir las que las contrarían en sus tendencias". (YI / JI: 24-06-1926)

"Sostengo que la verdadera educación del intelecto solo puede provenir del ejercicio y entrenamiento adecuado de los órganos corporales, o sea manos, pies, ojos, oídos, nariz, etc. En otras palabras, el uso inteligente de los órganos corporales, en un niño, es el mejor y más rápido medio para desarrollar su intelecto". (H: 8-03-1937)

"Está probado que es de poco provecho el desarrollo del cuerpo y de la mente si no le corresponde, paso a paso, el despertar del alma. Por adiestramiento espiritual entiendo la educación del corazón. Así, el desarrollo adecuado y completo de la mente, sólo se realiza cuando se da, paso a paso, con la educación de las facultades físicas y espirituales del niño. Forman un todo indivisible". (H: 17-04-1937)

"En mi esquema educacional, antes de dibujar o escribir, la mano debe manejar instrumentos. Así, los ojos leerán las imágenes de letras y palabras cuando ya conozcan otras cosas de la vida, y los oídos captarán los nombres y significado de las cosas y sentencias. El adiestramiento integral será natural, eficiente y, sin dudas, más rápido y el más barato del mundo". ( $\mathrm{H}:$ 28-08-1937)

"El hombre no es apenas mero intelecto, ni rudo cuerpo animal, ni sólo corazón o alma. La propia y armoniosa combinación de los tres es indispensable para la formación del hombre integral y constituye la verdadera base de la educación". (H: 11-09-1937)

Sobre educación para la paz y la no-violencia:

"Si deseamos realmente conseguir paz en el mundo, si deseamos, de hecho, emprender una guerra contra la guerra, tendremos que comenzar por los niños. Si ellos crecen en su inocencia natural, no tendremos que luchar, no tendremos que enseñar infructíferas resoluciones inútiles, sino que iremos de amor en amor y de paz en paz, hasta que finalmente los más alejados rincones del mundo se revistan de aquella paz y de aquel amor de los cuales, consciente o inconscientemente, el mundo está hambriento". (YI / JI: 19-11-1931)
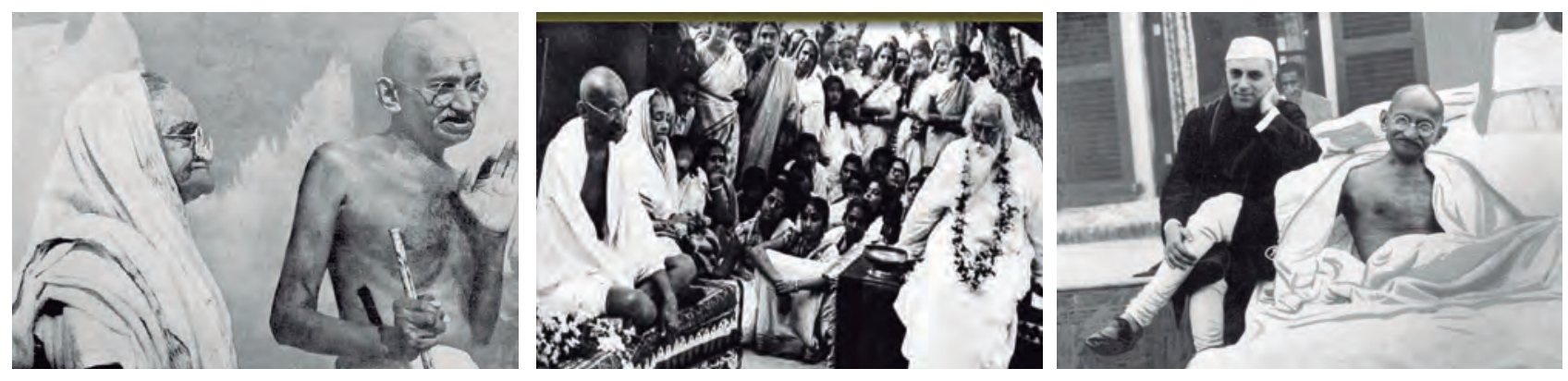

5. Metas y objetivos de su modelo educativo: sintéticamente, el modelo educativo gandhiano pretendía el logro de los objetivos y metas siguientes:

$\boldsymbol{\lambda}$ Logro de seres humanos con valores éticos y morales: dignidad y generosidad. Con conducta pacífica y no violenta, incluso con los enemigos. Pureza de corazón.

入 Fomento de la igualdad y la hermandad entre todos los seres humanos y todos los pueblos.

入 Coeducación de niños y niñas para el logro de la igualdad entre los hombres y las mujeres.

入 Aprecio por la naturaleza, la vida, los animales y las plantas.

त Desarrollo de comunidades cooperativas, solidarias, autosuficientes y con relaciones humanas positivas. Logro de la autonomía económica.
6. Educación para la paz y la no-violencia ("Satyagraha"): junto con Jesús y Tagore, Gandhi es sin duda el educador pacifista más importante de la historia. Y además predicó con su ejemplo a diario. Todo su sistema educativo, social y político se basa en la ley del amor, en la promoción de la paz entre todos los pueblos, la hermandad y el respeto entre los seres humanos y la práctica de la no-violencia. Toda su acción educativa gira en torno al logro en los escolares de un espíritu de paz y amor y de una conducta no violenta. Exclusión total de los castigos corporales.

7. Por un modelo escolar propio para India (distinto al modelo colonial): nadie rechazó la educación colonial de modo tan radical y absoluto como Gandhi, ni nadie propuso una alternativa tan extrema como la suya. Su crítica de la educación colonial 


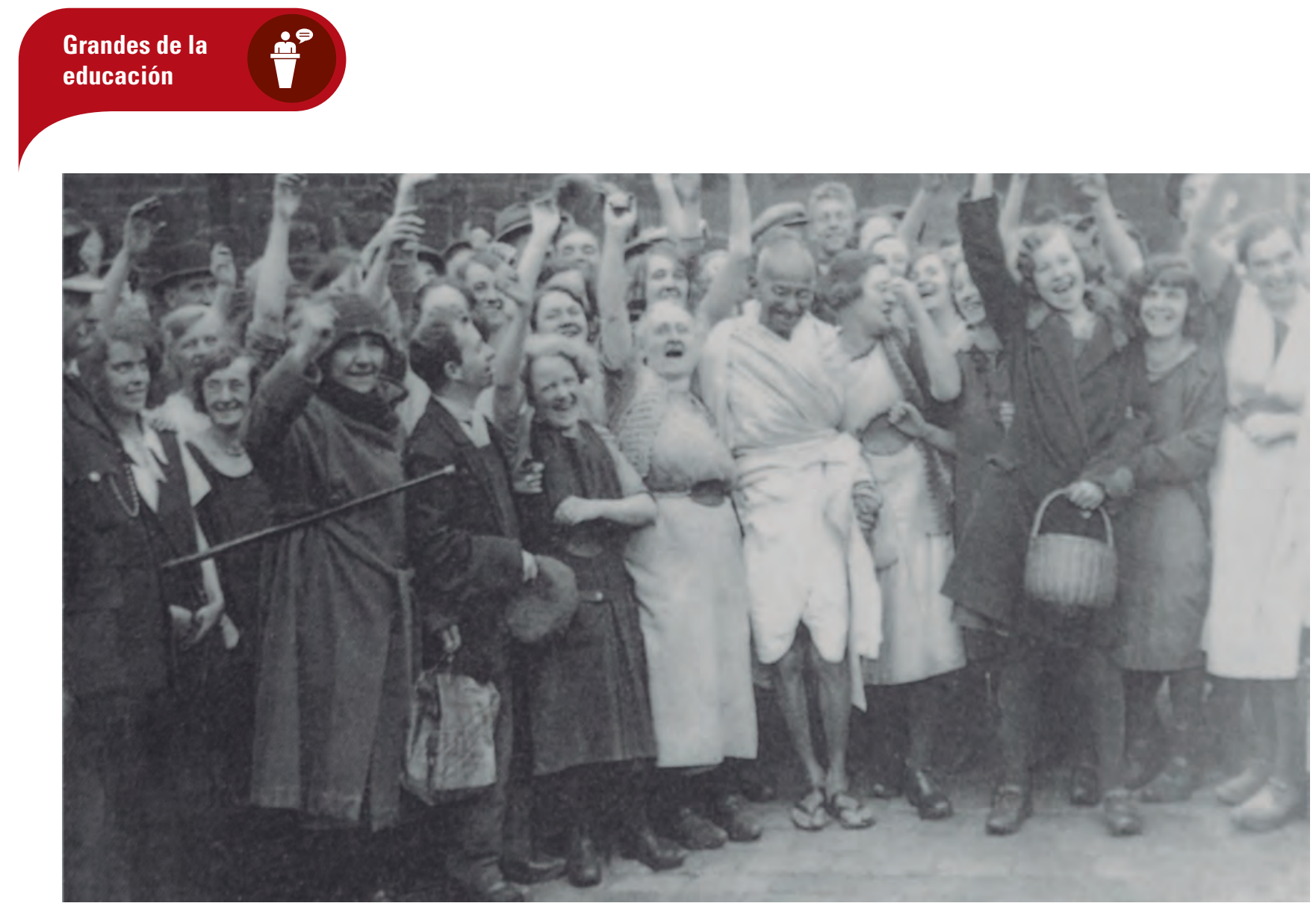

se inserta en la crítica global de la civilización occidental. Porque para él la colonización, incluido su programa educativo, era la negación de la verdad y de la no violencia, dos valores que consideraba supremos. Logro de la autoctonía cultural.

8. Importancia de la educación artística y el trabajo manual (artesanía productiva): el eje principal del modelo educativo gandhiano se centra en tomar como centro del programa de estudios -llevado a cabo en sus instituciones educativas- el desarrollo de trabajos manuales y artesanales variados, propios de los tradicionales oficios de la cultura india.

9. Crítica al uso del libro de texto: Gandhi escribió: "Si los libros de texto se tratan como un vehículo de enseñanza, la palabra viva del maestro tendrá muy poco valor. Un maestro que enseña a partir de un libro de texto no dará una visión original a sus discípulos" (en Harijan, 9-09-1939). Su plan de educación básica suponía el fin de la supeditación del maestro al libro de texto y al plan de estudios obligatorios. Su concepto de aprendizaje no se podía explicar plenamente con la ayuda de los libros de texto.

\section{Un hermoso texto gandhiano sobre la sonrisa}

"La sonrisa no cuesta nada y produce mucho. Enriquece a quien la recibe sin empobrecer a quien la da. No dura más que un instante, pero su recuerdo a veces es eterno. Nadie es tan rico que pueda pasar sin ella, y nadie es tan pobre que no pueda enrique- cerse con sus beneficios. Una sonrisa es descanso para los fatigados, luz para los decepcionados, alegría para los tristes y el mejor antídoto contra las preocupaciones. Una sonrisa no puede comprarse, no puede obtenerse por caridad, no puede robarse ni puede ser prestada, porque una sonrisa es algo que a nadie le produce beneficio, excepto que sea ofrecida espontáneamente y gratis. Y si, en el trato con nuestros compañeros, alguien está demasiado cansado para ofrecer una sonrisa, dale como regalo una de las tuyas, pues nadie precisa tanto de una sonrisa como aquella o aquel a quien no le queda ninguna que ofrecer" •

\footnotetext{
(A) DPRA SPBĝ MÂs

Attenborough, R. (director). (1982). Gandhi [cinta cinematográfica]. Reino Unido: Goldcrest Films.

GANDHI, M. (1988). Todos los hombres son hermanos. (10a ed.). Madrid: Atenas (Sociedad de Educación).

GANDHI, M. (2014). Mahatma Gandhi: autobiografía, historia de mis experiencias con la verdad. Madrid: Gaia. Mala, M. (Coord.). (1986). Mahatma Gandhi: Aquí y ahora. Antología de textos variados gandhianos. Buenos Aires: Edit. Hastinapura.

RawDing, F. W. (1991). Gandhi. Madrid: Akal.

Woodcock, G. (1995). Gandhi. Madrid: Planeta.
} 